\title{
Unilateral renal sympathetic denervation may reduce blood pressure in patients with refiractory hypertension
}

\author{
Aurelio Negro, ${ }^{1}$ Rosaria Santi, ${ }^{1}$ Antonio Manari, ${ }^{2}$ Franco Perazzoli ${ }^{1}$ \\ ${ }^{1}$ Internal Medicine and Hypertension Unit; and ${ }^{2}$ Interventistic Cardiology Unit, Arcispedale Santa Maria Nuova, Reggio Emilia, \\ Italy
}

\begin{abstract}
A 52-year-old Caucasian woman with essential resistant and refractory hypertension despite optimal medical therapy, including 6 different antihypertensive drugs was referred for the catheter-based renal denervation. Due to unfavourable anatomy because of non-critical fibromuscular dysplasia on the right renal artery, renal denervation of only the left renal artery was performed. Before and after the renal denervation, the patient's blood pressure was monitored by office measurements and ambulatory blood pressure measurements (ABPM). Before the procedure, the mean office blood pressure was 157/98 $\mathrm{mmHg}$; at ABPM, the mean blood pressure values were 145/94 mmHg. At 6 months of follow-up, the mean office blood pressure was $134 / 90 \mathrm{mmHg}$ and $121 / 76 \mathrm{mmHg}$ at ABPM. In latest 12 months of follow-up, office and ABPM blood pressure were 125/80 and $127 / 80 \mathrm{mmHg}$ respectively. This unique case suggests that unilateral renal denervation may be effective in lowering blood pressure in patients with refractory hypertension and unfavorable renal arteries anatomy.
\end{abstract}

\section{Introduction}

Resistant hypertension is defined as uncontrolled blood pressure (BP) in spite of concurrent use of $\geq 3$ antihypertensive agents ( $\mathrm{BP} \geq 140 / 90 \mathrm{mmHg}$ ) of different classes or as controlled blood pressure with the use of $\geq 4$ agents. ${ }^{1}$ Recently, the definition of refractory hypertension has been introduced, in order to describe patients with uncontrolled blood pressure in spite of concurrent use of $\geq 5$ antihypertensive drugs, which is the extreme phenotype of antihypertensive treatment failure. ${ }^{2}$ Patients with resistant hypertension suffer

Correspondence: Aurelio Negro, Internal Medicine and Hypertension Unit, Arcispedale Santa Maria Nuova, viale Risorgimento 80, 42100 Reggio Emilia, Italy.

E-mail: negro.aurelio@asmn.re.it

Key words: Renal fibrodysplasia; renal artery denervation; refractory hypertension.

Conflict of interest: the authors declare no potential conflict of interest.

Received for publication: 24 September 2014.

Revision received: 23 October 2014.

Accepted for publication: 27 October 2014.

This work is licensed under a Creative Commons Attribution NonCommercial 3.0 License (CC BY-NC 3.0).

CCopyright A. Negro et al., 2015

Licensee PAGEPress, Italy

Italian Journal of Medicine 2015; 9:362-366

doi:10.4081/itjm.2015.544 prematurely from target organ dysfunction and from early occurrence of cardiovascular, cerebrovascular and renal complications, leading to increased mortality. ${ }^{2,3}$ In the last years, catheter-based renal sympathetic denervation by radiofrequency has emerged as a new and effective method to treat resistant hypertension. After assessing that the renal arteries anatomy is favorable, usually by computed tomography or nuclear magnetic resonance angiography, renal denervation is performed bilaterally by introducing the treatment catheter into each renal artery and then delivering radiofrequency energy. Only few cases of unilateral renal denervation have been described until now, with conflicting results regarding the blood-pressure-lowering effect. ${ }^{4-6}$

We here report a case of refractory hypertension successfully treated with renal denervation, performed unilaterally instead of bilaterally because of the patient's renal arteries' unfavorable anatomy.

\section{Case Report}

A 52-year-old Caucasian woman with an approximately 12-year history of resistant essential hypertension was referred to us for percutaneous renal denervation. She was on a chronically low-sodium diet. Her body mass index was 28.5. She was not a smoker and denied the use of alcohol or drugs other than the antihypertensive agents. Her past medical history was otherwise unremarkable, except for a progressively severe and resistant hypertension. Secondary causes of hypertension had already been excluded elsewhere by proper evaluation. Despite op- 
timal medical therapy, including 6 different antihypertensive drugs (thiazides, angiotensin-converting enzyme inhibitors, calcium channel blockers, $\beta$-blockers, $\alpha$-blockers and spironolactone), her reported mean home blood pressure was 162/100 $\mathrm{mmHg}$. The patient was hospitalized for 5 days before the renal denervation, in order to exclude the diagnosis of pseudo-resistant hypertension and ascertain adequate therapeutic adherence, by prolonged staff components witnessed intake of antihypertensive drugs; plasma or urine metabolites of drugs were not measured. The mean office blood pressure was 157/98 $\mathrm{mmHg}$; at ambulatory BP monitoring measurement (ABPM), the mean values were 145/94 mmHg, with preserved night dipping. The electrocardiogram was unremarkable; on the echocardiogram, only mild left ventricular hypertrophy was detected. The patient's blood tests yielded the following results: plasma glucose: $89 \mathrm{mg} / \mathrm{dL}$; hemoglobin: $13.8 \mathrm{~g} / \mathrm{dL}$; creatinine: $0.62 \mathrm{mg} / \mathrm{dL}$; sodium: $140 \mathrm{mmol} / \mathrm{L}$; potassium: 4.8 $\mathrm{mmol} / \mathrm{L}$; the urinalysis was negative. The plasma renin activity was $0.9 \mathrm{ngAng} 1 / \mathrm{mL} / \mathrm{h}$ and serum aldosterone $176 \mathrm{pg} / \mathrm{mL}$ (normal range: 7-150 pg/mL). In order to evaluate the renal arteries anatomy, a preliminary computed tomography angiography (CTA) was performed. The CTA demonstrated a single artery for each kidney, the right renal artery showing moderate stenosis with a string of beads appearance, a characteristic radiological finding of fibromuscular dysplasia (Figure 1). However, a renal duplex ultrasound showed no significant stenosis, with a peak systolic velocity $<180 \mathrm{~cm} / \mathrm{s}$ in the whole course of the right
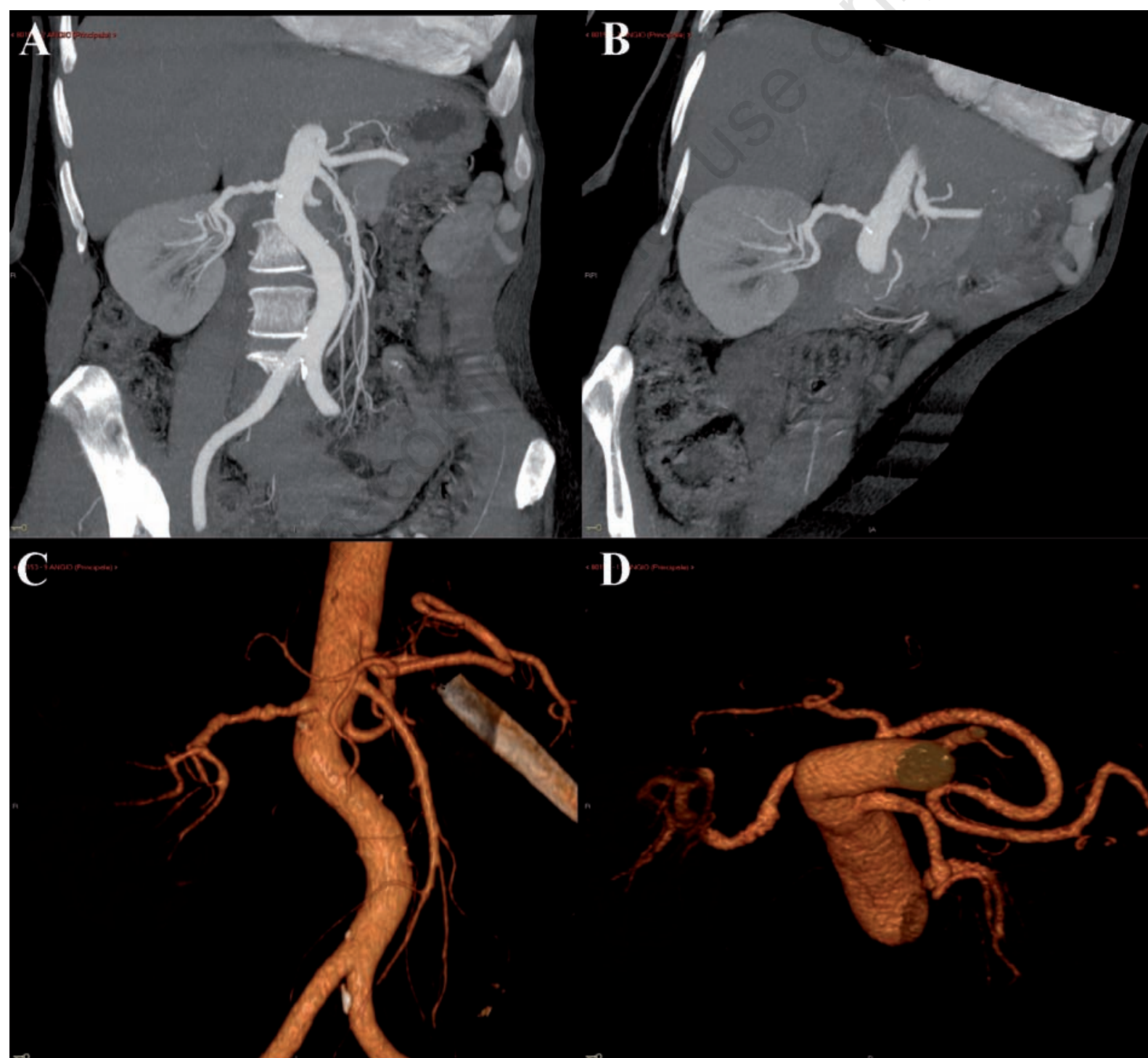

Figure 1. Computed tomography angiography. A-D) Axial and coronal planes showing moderate stenosis with string of beads of the right renal artery. 
renal artery. We judged the patient potentially suitable for unilateral renal denervation, after proper angiographic evaluation. The procedure was explained in detail to the patient and an informed consent was obtained. Under conscious sedation, femoral artery access was obtained with the standard endovascular technique, using a 6 F sheath, and a bilateral selective renal angiography was performed. The angiography confirmed a moderate stenosis in the right renal artery (Figure 2). Moreover, the trans-catheter measurements showed no blood pressure gradient $(3 \mathrm{mmHg})$. The left renal artery showed a diameter of $6 \mathrm{~mm}$ and a length of $3.5 \mathrm{~mm}$. Thereafter, the treatment catheter (Symplicity by Medtronic Inc., Northridge, CA, USA) was inserted into the left renal artery and radiofrequency ablations of 8 watts or less, lasting up to $2 \mathrm{~min}$ each, were applied to obtain five ablations. During ablation, the catheter system monitored tip temperature and impedance, altering radiofrequency energy delivery in response to a predetermined algorithm. The final angiogram showed no lesions in the left renal artery. The patient was discharged two days later in stable condition and on six antihypertensive drugs.

In Table 1, the baseline and follow-up BP values are presented. Notably, at two months follow-up an autonomous reduction of antihypertensive drugs was reported, with interruption of doxazosin because of satisfactory blood pressure control. At 9 months of follow-up, only office blood pressure value of 122/80 $\mathrm{mmHg}$ was available from refuse of ABPM by the patient. However, the latest 12 months of follow-up confirmed profound blood-pressure-lowering effect, with office and $24 \mathrm{~h}$-ABPM blood pressure values of $125 / 80$ and $127 / 80 \mathrm{mmHg}$ respectively, with only three antihypertensive agents (lisinopril, spironolactone, amlodipine).

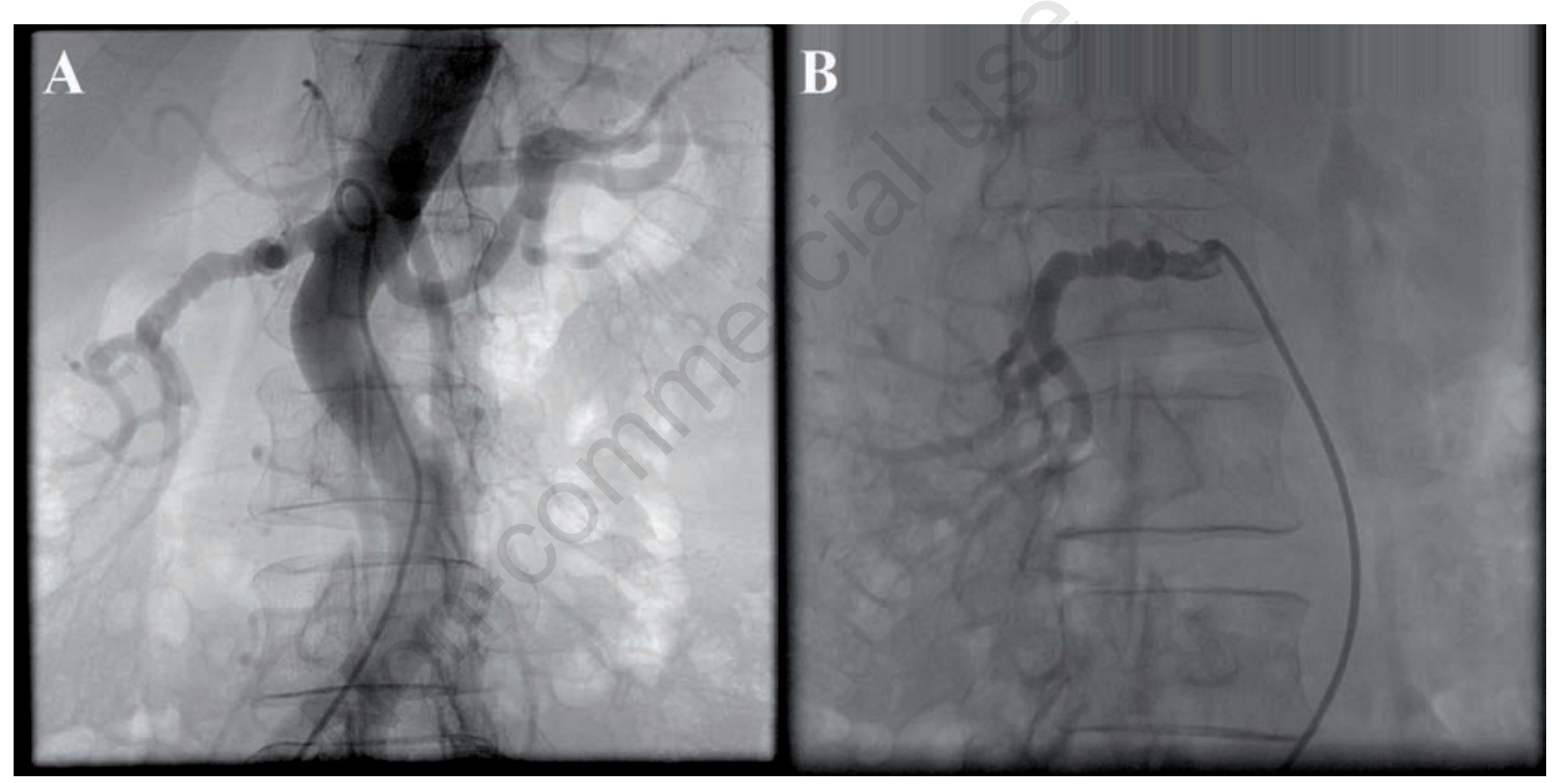

Figure 2. Renal angiography. A) Angiography confirms moderate right renal artery stenosis by fibromuscular dysplasia; B) measurement trans-catheter of blood pressure gradient.

Table 1. Blood pressure values at baseline and at follow-up.

\begin{tabular}{lccccc}
\hline & $\begin{array}{c}\text { Office BP } \\
(\mathbf{m m H g})\end{array}$ & $\begin{array}{c}\text { Mean } \mathbf{2 4} / \mathbf{h} \\
\text { ABPM (mmHg) }\end{array}$ & $\begin{array}{c}\text { Mean diurnal } \\
\text { ABPM (mmHg) }\end{array}$ & $\begin{array}{c}\text { Mean nocturnal } \\
\text { ABPM (mmHg) }\end{array}$ & $\begin{array}{c}\text { Antihypertensive } \\
\text { drugs (n) }\end{array}$ \\
\hline Baseline & $157 / 98$ & $145 / 94$ & $149 / 95$ & $130 / 87$ & 6 \\
\hline 2 months & $130 / 90$ & $136 / 89$ & $143 / 91$ & $126 / 77$ & 5 \\
\hline 6 months & $134 / 90$ & $121 / 76$ & $126 / 82$ & $112 / 65$ & 5 \\
\hline 9 months & $122 / 80$ & n.a. & n.a. & n.a. & 5 \\
\hline 12 months & $125 / 80$ & $127 / 80$ & $132 / 84$ & $118 / 73$ & 3 \\
\hline
\end{tabular}

BP, blood pressure; ABPM, ambulatory BP measurement; n.a., not available. 


\section{Discussion and Conclusions}

Hypertension is a leading risk factor influencing the global burden of cardiovascular diseases. The treatment of hypertension remains suboptimal in many patients, with subsequent, inadequately controlled blood pressure. Notably, patients whose target BP values are not reached despite a triple therapy, including a diuretic at the maximum tolerated dose, are defined as having resistant hypertension. ${ }^{1}$ Patients with resistant hypertension are bearing a very-high cardiovascular risk. ${ }^{2,3}$

An increased sympathetic activity has been shown to characterize resistant hypertension and, historically, radical surgical methods for sympathetic denervation have been successful in lowering blood pressure in severely hypertensive patients. ${ }^{7}$ Recently, percutaneous renal denervation has been introduced as a new method to treat resistant hypertension. The procedure entails a favorable anatomy of the renal arteries and, above all, it is performed bilaterally into both renal arteries. To our knowledge, only few cases of unilateral renal denervation have been described, with conflicting results about the blood-pressure-lowering effect. For instance, Ukena et al. showed that unilateral renal denervation, in ten patients with resistant hypertension and suboptimal anatomy, determined a comparable reduction of blood pressure to the one obtained in the control group which underwent bilateral renal denervation. ${ }^{6}$ The same results were reported by Armaganijan et al. in a single patient, ${ }^{5}$ whereas other Authors denied any effect. ${ }^{4}$ Our unique case suggests that unilateral renal denervation may reduce blood pressure in patients with refractory hypertension and unfavorable renal arteries anatomy. Unlike other reports, our case is remarkable because the fibrodysplastic lesions affecting the right renal artery anyway not significant at renal duplex ultrasound evaluation and transcatheter pressure gradient measurements. We believe that the sustained and prolonged blood pressure reduction in our patient is not a simple placebo phenomenon but a true blood pressure-lowering effect of the renal denervation, especially if one considers the progressive resistance of long standing hypertension coupled with the good therapeutic adherence of our patient.

In former studies, renal denervation was associated with significant and persistent reduction in systolic and diastolic blood pressure beyond those produced by medical therapy, ${ }^{8,9}$ but with a failure of some patients to experience a drop in arterial pressure. The most commonly offered explanation for this is that in these patients sympathetic activation is not the primary pathophysiology, but this might not be true as surgical renal denervation commonly reduces blood pressure in experimental models of hypertension in which sympathetic nervous activation is normal. ${ }^{7}$
Moreover, recent observations suggest that the real reason might more commonly be that in non-responder patients, the denervation has failed technically. In fact, renal denervation in humans is very incomplete, non-uniform from patient to patient, and achieved with difficulty mainly because the sympathetic nerves converged on the renal arteries distally, near the renal artery branch point. ${ }^{10}$ Therefore, the ablative energy should be preferentially focused on the distal renal artery, and on the full circumference of renal arteries but this is often not done. Among clinical studies of renal denervation, only in the HTN-1 trial renal denervation was confirmed by measurement of norepinephrine spillover, which decreased on average of $47 \%$, apparently sufficient in that the antihypertensive response was adequate. ${ }^{8}$ Nevertheless, the recent Symplicity HTN-3 trial did not show a significant reduction in blood pressure after renal denervation, compared to a sham control with maximal medical therapy, in a large cohort of patients with resistant hypertension. ${ }^{11}$ However, the changes in systolic blood pressure from baseline show a very wide variability, with values between $-78 \mathrm{mmHg}$ and $14 \mathrm{mmHg}$ in the renal denervation group, and between $-43 \mathrm{mmHg}$ and $41 \mathrm{mmHg}$ in the control group. Presumably, the sympathetic over-activity is crucial in some patients while in others the sympathetic nervous tone might be less important than expected. There are several other possibilities why Symplicity HTN-3 did not confirm the favorable results of previous trials, for instance a not verified drug adherence or procedural discrepancies as incomplete ablation. In fact, we now know that a circumferential renal ablation was not achieved in a disturbing $69 \%$ of the renal denervation procedure. ${ }^{12}$

Our single center experience also supported the efficacy of this method in patients with resistant hypertension from daily clinical practice. ${ }^{13}$ Truly resistant hypertensive patients certainly exist, but are rarer than currently estimated. Thus, our policy is not an undisturbed practice of renal denervation, but that of a sound and meditated clinical reasoning accordingly to expert consensus document for a proper selection of patients. ${ }^{14}$ Unfortunately, we have no clear predictors of clinical response to renal denervation at this moment. However, as suggested by recent data, the higher the baseline BP is the greater its reduction will be after renal denervation..$^{15}$ Thus, as in our case, individuals with refractory hypertension may configure a better-responding subgroup.

We are aware of potential risks on integrity of renal arteries, as emphasized by optical coherence tomography, both in animals and humans, with edema and thrombus formation at the ablation site not apparent with angiography. ${ }^{16,17}$ However, a dual antiplatelet therapy seems to be a suitable treatment. To our knowledge, up to now at least 13 cases of significant 
renal artery stenosis have been documented after renal denervation using different renal ablation systems; therefore, that complication is a matter of concern. ${ }^{18}$ We believe that the patients need a prolonged and adequate follow-up in expert centers. In our case, the current 12 months follow-up clearly shows no complications on renal arteries and renal function.

Sympathetic renal blood pressure regulation involves efferent and afferent fibers from and to central nervous system. The nerves reach the kidney from the aorta, following the course of the renal arteries, in whose adventitia they are located. They regulate the sodium reabsorption and the vascular tone of afferent and efferent arterioles. They also increase renin release from juxtaglomerular cells resulting in angiotensin II production and increase in aldosterone secretion from adrenal glands. However, there are fibers proceeding from one kidney to the other, which modulate the socalled reno-renal reflex, resulting in diuresis and natriuresis. ${ }^{7}$ This could possibly explain the efficacy of unilateral renal denervation.

In conclusion, we propose that, in patients with refractory hypertension and unfavorable renal arteries anatomy, the unilateral renal denervation may be effective in lowering blood pressure.

\section{References}

1. Calhoun DA, Jones D, Textor S, et al. American Heart Association Scientific statement on resistant hypertension: diagnosis, evaluation, and treatment. Hypertension 2008;51:1403-19.

2. Calhoun DA, Booth JN, Oparil S, et al. Refractory hypertension. Determination of prevalence, risk factors, and comorbidities on a large population-based cohort. Hypertension 2014;53:451-8.

3. Cuspidi C, Macca G, Sampieri L, et al. High prevalence of cardiac and extracardiac target organ damage in refractory hypertension. J Hypertens 2011;19:2063-70.

4. Vaclavik J, Taborsky M, Richter D. Unilateral catheterbased renal sympathetic denervation in resistant arterial hypertension shows no blood pressure-lowering effect. Clin Exp Hypertens 2013;35:192-4.

5. Armaganijan L, Staico R, Abizaid A, et al. Unilateral renal artery sympathetic denervation may reduce blood pressure in patients with resistant hypertension. J Clin Hypertens 2013;15:606.
6. Ukena C, Mahfoud F, Dalinghoff M, et al. Comparison of unilateral versus bilateral renal denervation in patients with resistant hypertension. Eur Heart J 2013;34:495 (Abstr. 2704).

7. DiBona GF, Esler M. Translational medicine: the antihypertensive effect of renal denervation. Am J Physiol Regul Integr Comp Physiol 2010;298:R245-53.

8. Krum H, Schlaich M, Whitbourn R, et al. Catheter-based rena sympathetic denervation for resistant hypertension: a multicentre safety and proof-of-principle cohort study. Lancet 2009;373:1275-81.

9. Esler MD, Krum H, Sobotka PA, et al. Renal sympathetic denervation in patients with treatment resistant hypertension: a randomized controlled trial. Lancet 2010;376:1903-9.

10. Esler M, Bishop LF. Lecture: Treatment of drug-resistant hypertension with renal denervation: rationale, results and recent challenges. American College of Cardiology 63rd Annual Scientific Session, 29 March 2014, Washington, DC, USA.

11. Bhatt DL, Kandzari DE, O’Neill WW, et al. Symplicity HTN-3 Investigators. A controlled trial of renal denervation for resistant hypertension. NEJM 2014;370: 1393-401.

12. Schmieder RE. Renal denervation - a valid treatment option despite SYMPLICITY HTN-3. Nat Rev Cardiol 2014; 11:638.

13. Negro A, Manari A, Santi R, et al. Endovascular radiofrequency renal denervation in resistant hypertension: a single center experience. Ital J Med 2014; 8:29-34.

14. Volpe M, Agabiti Rosei E, Ambrosioni E, et al. Renal artery denervation for treating resistant hypertension. High Blood Press Cardiovasc Prev 2012;19:237-44.

15. Mahfoud F, Ukena C, Schmieder RE, et al. Ambulatory blood pressure changes after renal sympathetic denervation in patients with resistant hypertension. Circulation 2013;128:132-40.

16. Steigerwald K, Titova A, Malle C, et al. Morphological assessment of renal arteries after radiofrequency catheter-based sympathetyc denervation in a porcine model. J Hypertens 2012;30:2230-9.

17. Templin C, Jaguszewski M, Ghadri JE, et al. Vascular lesions induced by renal nerve ablation as assessed by optical coherence tomography: pre- and post-procedural copmarison with the Symplicity catheter system and the EnligHTN multi-electrode renal denervation catheter. Eur Heart J 2013;34:2141-8.

18. Persu A, Jin Y, Elmula F, et al. Renal denervation after Symplicity HTN-3: an update. Curr Hypertens Rep 2014; 16:460-8. 